\title{
Performance Analysis of the Organic Rankine Cycle (ORC) System under Engine Various Operating Conditions
}

\author{
Kai Yang and Hongguang Zhang
}

\begin{abstract}
Though experiments, variation of a diesel engine exhaust energy is studied, a set of ORC system is designed and set up. The variation of running performance of an ORC (organic Rankine cycle) system under engine varying working conditions is analyzed, the effects of evaporating pressure on the ORC system is discussed, the improvement extent of engine thermal efficiency, brake specific fuel consumption (BSFC) after the engine is coupled with a set of an ORC system is studied. The research shows that, when evaporating pressure being $3 \mathrm{MPa}$, engine speed being $2200 \mathrm{r} / \mathrm{min}$ and engine torque being $1200 \mathrm{~N} \cdot \mathrm{m}$ separately, the net power output of the ORC system, engine thermal efficiency increasing ratio (ETEIR), and the Improvement ratio of BSFC all hits the maximum values, being $22.41 \mathrm{~kW}, 8.085 \%, 7.423 \%$ respectively.
\end{abstract}

Index Terms - Vehicle diesel engine, waste heat recovery, organic Rangine cycle, various operating conditions.

\section{INTRODUCTION}

IC (internal combustion) engines have taken away a good deal of oil resources, while their thermal efficiencies still have deep potential to improve. Most energy released from the fuel combustion in the cylinder has been carried off by the exhaust and cooling medium, wasting energy and causing severe environmental problems [1]. Therefore, how to highly effectively recover and utilize this kind of energy is very necessary, with which the energy consumption and pollutant emission all can be reduced.

The ORC technology, used for heat-work conversion, can convert the medium-low waste heat into useful work for output, and has been studied and applied in many areas [2]-[6]. Pierobon et al. [7] designed an organic Rankine cycle system to recover the waste heat from a gas turbine. El-Emam et al. [8] analyzed the running performances on a geothermal regenerative ORC system. Wang et al. [9] designed an organic Rankine cycle system driven by solar energy. Marion et al. [10] analyzed the effects of wind, ambient temperature and solar radiation on the simultaneous productions of mechanical work and heat by a solar Rankine cycle.

Currently, some scholars are considering how to use the ORC technology to recover the exhaust heat of the IC engine [11]-[14]. Peris et al. [15] utilized an organic Rankine cycle system to recover the coolant energy of engines. Meinel et al. [16] recovered exhaust energy from

Manuscript received June 30, 2014; revised August 26, 2014.

The authors are with the Beijing University of Technology, Pingleyuan No.100, 100124 Beijing, China (e-mail: ykai104@163.com, zhg5912@263.net). engines by using an organic Rankine cycle system. Hajabdollahi et al. [17] studied the thermal efficiency and cost of the diesel engine-ORC system. Domingues et al. [18] analyzed the exhaust waste heat recovery potential by using a Rankine cycle. In conclusion, ORC system can effectively recover the waste heat, thereby, increase the engine thermal efficiency.

In this paper, we have achieved a full set of experiment data of a diesel engine in the whole operating range, also we studied variation of the exhaust energy and the running performance of the ORC system in engine varying range. Afterwards, we discussed the effects of the evaporating pressure on the ORC system performance, and analyzed the improve degree of the diesel engine thermal efficiency when the engine is coupled with an ORC system.

\section{DIESEL ENGINE EXPERIMENTS}

With experiment, we achieved the test data of a six-cylinder four-stroke vehicle diesel engine. To highly effectively recover and utilize the waste heat in the engine whole operating range, we have studied the variation of the exhaust energy in different working conditions. Through equation (1), the exhaust energy can be computed.

$$
\dot{Q}_{\mathrm{ava}}=c_{\mathrm{p}} \dot{m}_{\mathrm{exh}}\left(T_{\mathrm{exh} \_1}-T_{\min }\right)
$$

where, $\dot{Q}_{\mathrm{ava}}$ is the maximum exhaust energy of the diesel energy, $c_{\mathrm{p}}$ is the constant-pressure specific heat of the diesel engine, $\dot{m}_{\mathrm{exh}}$ is the mass flux, $T_{\text {exh_1 }}$ is the exhaust temperature, $T_{\min }$ is the minimum temperature the exhaust can reach to when go through the heat exchanger. Via experiment, we achieved linear relation by matching the $c_{\mathrm{p}}$ with the exhaust temperature.

$$
c_{\mathrm{P}}=0.00025 T_{\mathrm{exh} \_1}+0.99
$$

Fig. 1 is the variation of the available exhaust energy under engine varying working conditions. With the increase of the engine torque and speed, the available exhaust energy increase gradually. When engine speed being $2200 \mathrm{r} / \mathrm{min}$ and engine torque being $1200 \mathrm{~N} \cdot \mathrm{m}$, the available exhaust energy hits the maximum value, which is roughly $290 \mathrm{~kW}$. The rated output power of this diesel engine is $280 \mathrm{~kW}$.

Fig. 2 is the variation of the Brake Specific Fuel Consumption (BSFC) of the diesel engine. As can be seen, 
when the engine running at high speed and low torque working condition, BSFC has bigger values; when engine speed being roundly $1100 \mathrm{r} / \mathrm{min}$ and torque being roughly $1300 \mathrm{~N} \cdot \mathrm{m}, \mathrm{BSFC}$ is minimum.

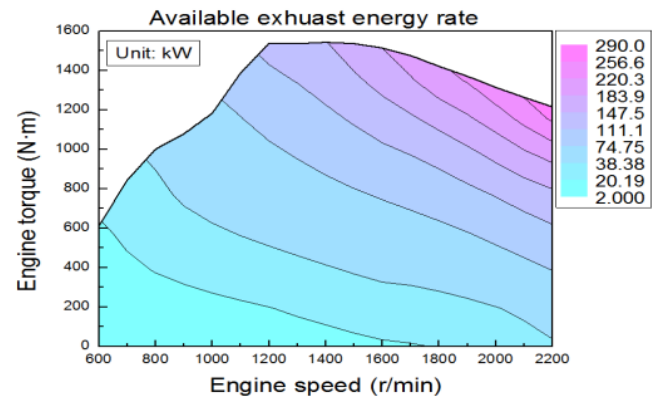

Fig. 1. The variation of the available exhaust energy.

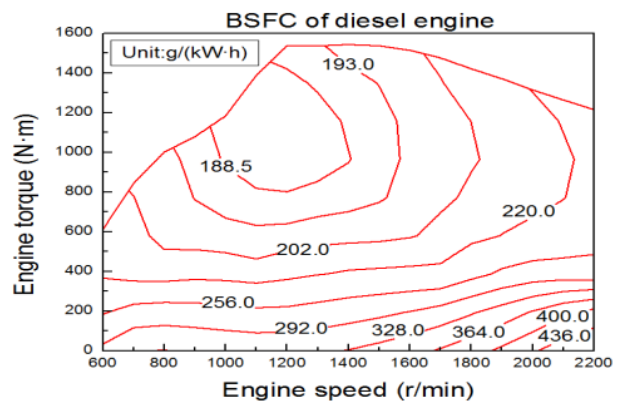

Fig. 2. The variation of the BSFC of the diesel engine.

\section{ORC MODEL INTRODUCTION}

A set of simplified ORC system is designed to recover the exhaust energy of the vehicle diesel engine, the exhaust temperature, as the high temperature heat source of the ORC system, is used for heating the organic working fluids. Fig. 3 is the schematic diagram of the ORC system, mainly covering the diesel engine, evaporator, expander, condenser, liquid reservoir and pump. The working fluids chosen for the ORC system is R245fa.

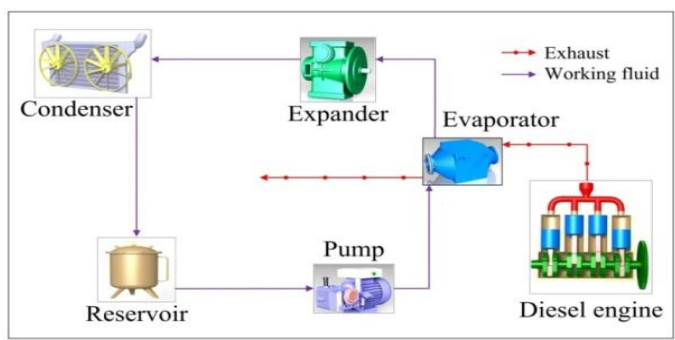

Fig. 3. The schematic diagram of the ORC system.

Fig. 4 is T-s diagram of the vehicle diesel engine-ORC combined system.

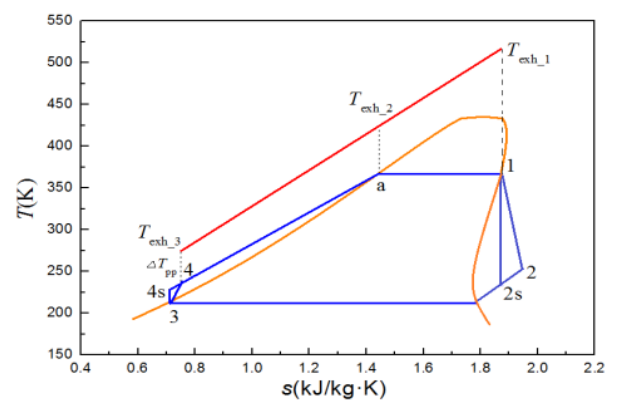

Fig. 4. T-s diagram of vehicle diesel engine-ORC combined system.
The power output of the expander is computed with the equation below.

$$
\dot{W}_{\mathrm{s}}=\dot{m}\left(h_{1}-h_{2}\right)=\dot{m}\left(h_{1}-h_{2 \mathrm{~s}}\right) \eta_{\mathrm{s}}
$$

The heat exchange amount of the condensation process is computed with the equation below.

$$
\dot{Q}_{\mathrm{c}}=\dot{m}\left(h_{2}-h_{3}\right)
$$

The power consumed by the pump is computed with the equation below.

$$
\dot{W}_{\mathrm{p}}=\dot{m}\left(h_{4}-h_{3}\right)=\frac{\dot{m}\left(h_{4 \mathrm{~s}}-h_{3}\right)}{\eta_{\mathrm{p}}}
$$

The heat exchange amount of the heat absorbing process is computed with the equation below.

$$
\dot{Q}_{\mathrm{e}}=\dot{m}\left(h_{1}-h_{4}\right)
$$

The net power output of the ORC system.

$$
\dot{W}_{\text {net }}=\dot{W}_{\mathrm{s}}-\dot{W}_{\mathrm{p}}
$$

In order to evaluate the running performance of the combined system, we proposed a concept called engine thermal efficiency increasing ratio (ETEIR), output energy density of working fluid (OEDWF), waste heat recovery efficiency (WHRE) and Improvement ratio of brake specific fuel consumption.

The equation for computing the ETEIR is as follows:

$$
\eta_{\text {ETEIR }}=\frac{\left(\dot{W}_{\text {ice }}+\dot{W}_{\text {net }}\right) / \dot{Q}_{\text {fuel }}-\dot{W}_{\text {ice }} / \dot{Q}_{\text {fuel }}}{\dot{W}_{\text {ice }} / \dot{Q}_{\text {fuel }}}
$$

The equation for computing the OEDWF is as follows:

$$
\text { OEDWF }=\frac{\dot{W}_{\text {net }}}{\dot{m}}
$$

The equation for computing the WHRE is as follows:

$$
\eta_{\text {WHRE }}=\frac{\dot{W}_{\text {net }}}{\dot{Q}_{\text {ava }}}
$$

Improvement rate of BSFC is computed with equation below.

$$
\eta_{\text {bsfc }}=\frac{\dot{m}_{\text {fuel }} / \dot{W}_{\text {ice }}-\dot{m}_{\text {fuel }} /\left(\dot{W}_{\text {ice }}+\dot{W}_{\text {net }}\right)}{\dot{m}_{\text {fuel }} / \dot{W}_{\text {ice }}}
$$

\section{INTERPRETATION OF RESULT}

With research, we concluded that, when engine torque is 
less than $300 \mathrm{~N} \cdot \mathrm{m}$, the appearing position of the pinch point temperature difference between engine exhaust and working fluids changes, therefore, in the following analysis, the working conditions of the engine torque being less than $300 \mathrm{~N} \cdot \mathrm{m}$ is not considered. Fig. 5 is the variation of the net power output under different evaporating pressures. With increase of engine speed and torque, the net power output of the ORC system increase gradually. This mainly because, with increase of the engine speed and torque, the available exhaust energy increase gradually, then more working fluids can be evaporated for doing work. When the engine running condition is constant, the net power output of the organic Rankine cycle system increase gradually with increase of evaporating pressure. When evaporating pressure being $3 \mathrm{MPa}$ and engine speed being $2200 \mathrm{r} / \mathrm{min}$, the net power output of the ORC system hits the maximum value, roundly $22.41 \mathrm{~kW}$.

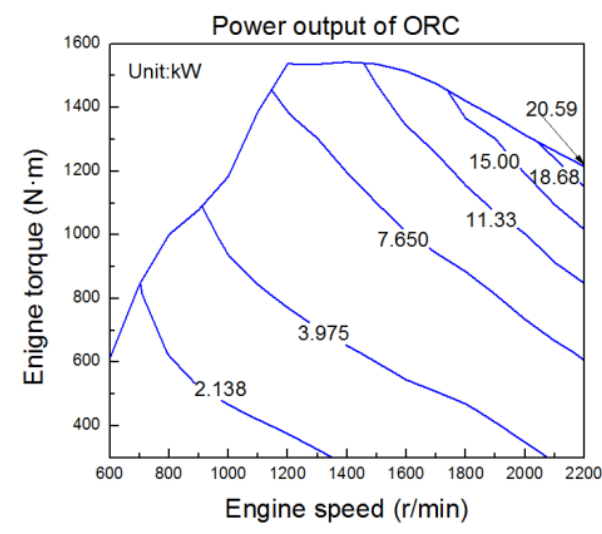

(a). evaporating pressure $=1 \mathrm{MPa}$

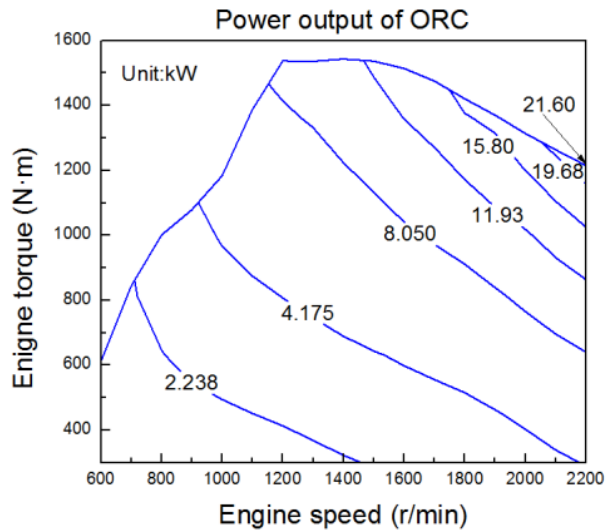

(b). evaporating pressure $=2 \mathrm{MPa}$

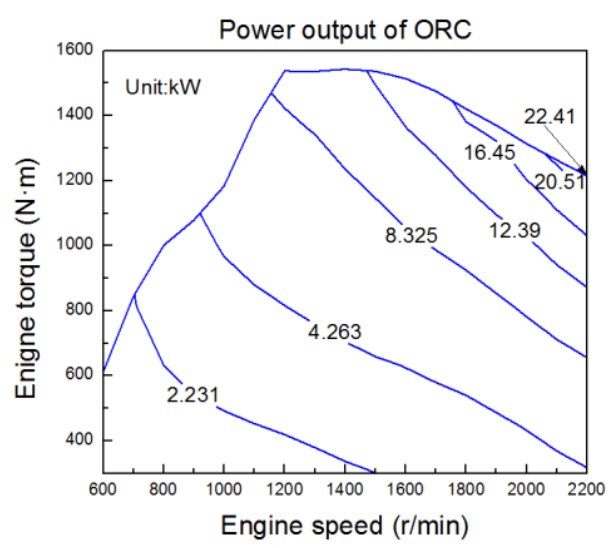

(c). evaporating pressure $=3 \mathrm{MPa}$

Fig. 5. Variation of the net power output under different evaporating pressures.
Fig. 6 shows the variation of the mass flux of the working fluids at different evaporating pressures. When evaporating pressure being constant, with the increase of engine speed and torque, the mass flux of the working fluids increase gradually. This mainly depends on the amount of the available engine exhaust energy. When the engine runs at constant working condition, with the increase of the evaporating pressure, the net power output of the ORC system decreases gradually. It can be seen from the figure, under different engine working conditions, the mass fluxes of the working fluids evaporated are different. Therefore, to highly effectively recover and utilize the exhaust energy under engine whole operating range, it's necessary to regulate the mass flux of the working fluids in accordance with the engine running conditions.

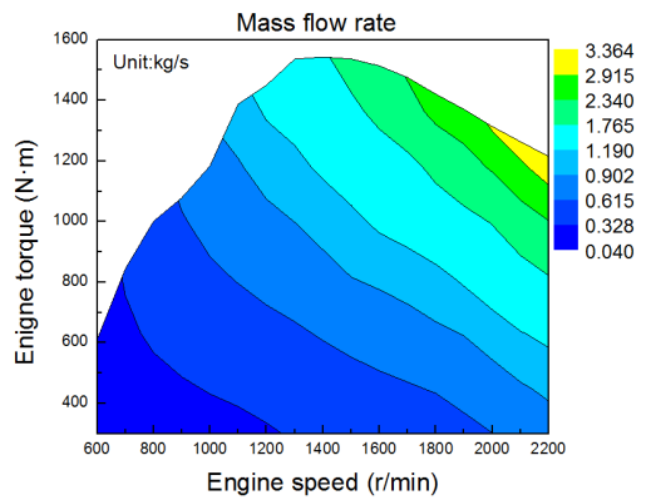

(a) evaporating pressure $=1 \mathrm{MPa}$

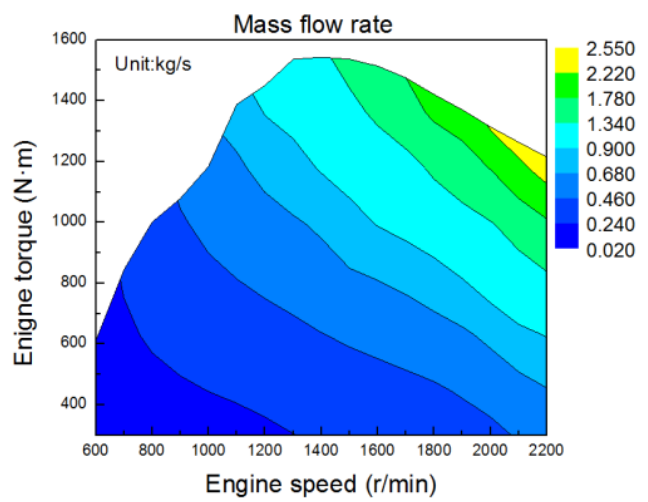

(b) evaporating pressure $=2 \mathrm{MPa}$

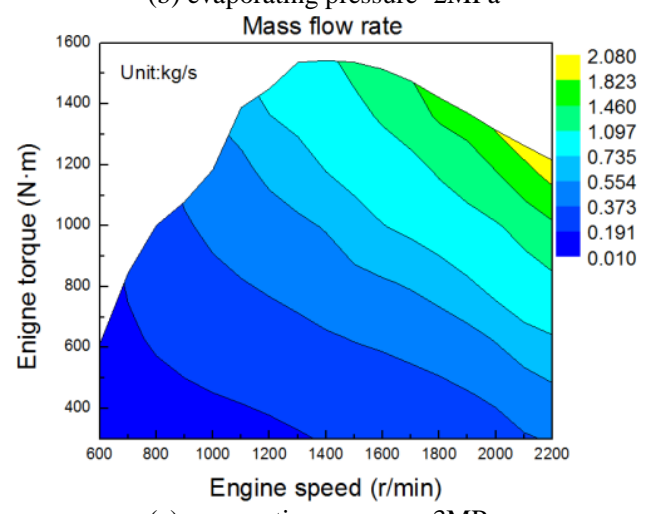

(c) evaporating pressure $=3 \mathrm{MPa}$

Fig. 6. Variation of the mass flux of the working fluids.

It can be seen from Fig. 5 and Fig. 6, with increase of evaporating pressure, the net power output of the ORC system increase, while the mass flux of the working fluids decreases, explaining that, at different evaporating pressures, the power outputs of the unit organic working fluids are 
different. Fig. 7 is the variation of the OEDWF under different evaporating pressures. With increase of evaporating pressure, OEDWF increases gradually. When evaporating pressure being $3 \mathrm{MPa}, \mathrm{OEDWF}$ is the maximum value, roughly $10.77 \mathrm{~kJ}$.

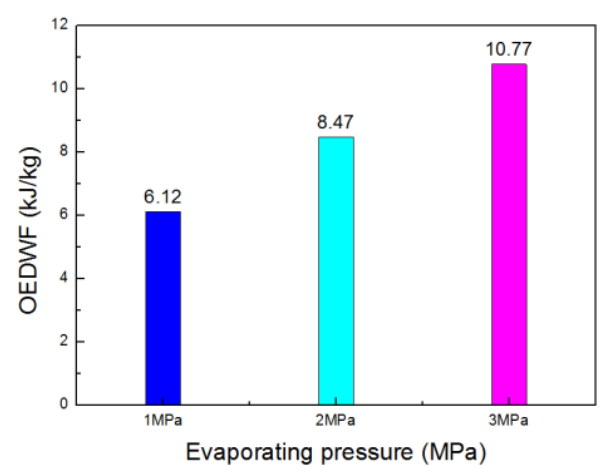

Fig. 7. Variation of the OEDWF under different evaporating pressures.

It can be concluded from the analysis above, when evaporating pressure being $3 \mathrm{MPa}$, the ORC system has the optimal performance. In the following study, we only discuss, when evaporating pressure being $3 \mathrm{MPa}$, the running performance of the combined system. In order to evaluate the improve degree of the engine thermal efficiency after the engine is coupled with a set of ORC system, we propose a indicator called engine thermal efficiency increasing ratio (ETEIR). Fig. 8 is the variation of the ETEIR under engine whole operating range. It can be seen from the figure, the variation of ETEIR is relatively complex, when engine speed being $2200 \mathrm{r} / \mathrm{min}$ and torque being $1200 \mathrm{~N} \cdot \mathrm{m}$, ETEIR has the maximum value, roundly $8.085 \%$.

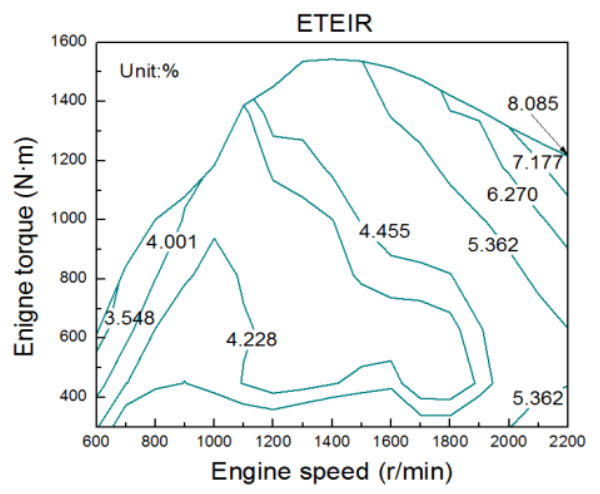

Fig. 8. Variation of the ETEIR under engine whole operating range.

Fig. 9 shows the improvement ratio of the engine BSFC after the engine is coupled with the ORC system. When engine runs at high speed and high torque condition, with increase of engine speed and torque, the improvement ratio of the BSFC increase gradually. When engine speed being $2200 \mathrm{r} / \mathrm{min}$ and engine torque being $1200 \mathrm{~N} \cdot \mathrm{m}$, the improvement ratio of the BSFC hits the maximum value, roughly $7.423 \%$. This is mainly affected by the exhaust temperature, the net power output of the ORC system and the engine power output as well.

To evaluate the extent of recovering and utilizing the energy exhaust energy, we propose an indicator called waste heat recovery efficiency (WHRE). Fig. 10 is the variation of WHRE under engine different working conditions. WHRE increase with the engine torque. When engine speed being
$2200 \mathrm{r} / \mathrm{min}$ and engine torque being $1200 \mathrm{~N} \cdot \mathrm{m}$, WHRE hits the maximum value, roundly $7.729 \%$. This primarily influenced by two factors: engine exhaust energy and the net power output of the ORC system.

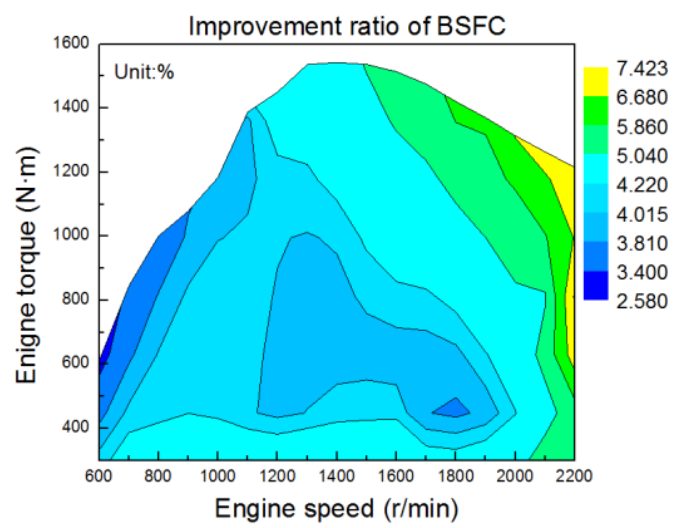

Fig. 9. Improvement ratio of BSFC for the engine.

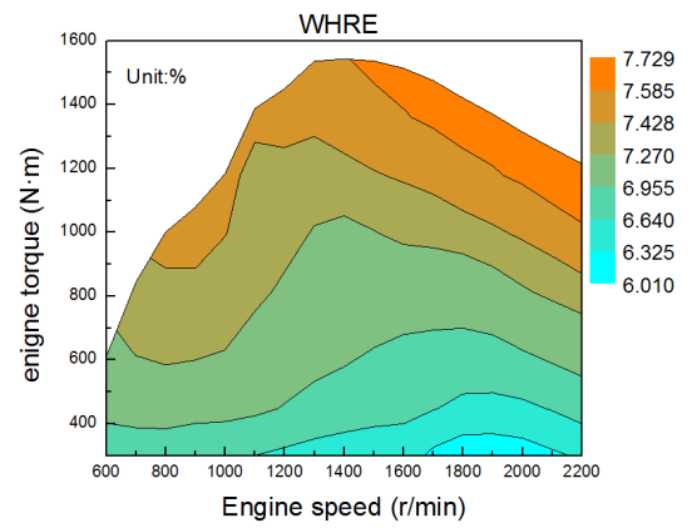

Fig. 10. Variation of WHRE under engine different working conditions.

\section{CONCLUSIONS}

This paper is summarized as the following three points:

1) With the increase of the evaporating pressure, the net power output of the ORC system increase, while the mass flux of the working fluids decreases gradually. This explains, with the increase of evaporating pressure, OEDWF increase gradually, when evaporating pressure being $3 \mathrm{MPa}$, OEDWF hits the maximum value, roundly $10.77 \mathrm{~kJ}$

2) Generally, the exhaust energy of the diesel engine varies with time, to highly effectively recover and utilize the exhaust energy under the whole diesel energy operating range, should regulate the mass flux of the working fluids in line with the varying of the exhaust energy.

3) When engine speed being 2200r/min and engine speed being $1200 \mathrm{~N} \cdot \mathrm{m}$, the net power output of the ORC system, engine thermal efficiency increasing ratio (ETEIR), waste heat recovery efficiency (WHRE) and the Improvement ratio of BSFC all hit the maximum value, being $22.41 \mathrm{~kW}, 8.085 \%, 7.729 \%, 7.423 \%$ respectively.

\section{ACKNOWLEDGMENTS}

This work was sponsored by the National Natural Science Foundation of China (Grant No. 51376011), Scientific 
Research Key Program of Beijing Municipal Commission of Education (Grant No. KZ201410005003), and Research Fund for the Doctoral Program of Higher Education of China (Grant No. 3C005015201301).

\section{REFERENCES}

[1] V. Dolz, R. Novella, A. García, and J. Sánchez, "HD diesel engine equipped with a bottoming Rankine cycle as a waste heat recovery system, part 1: study and analysis of the waste heat energy," Applied Thermal Engineering, vol. 36, pp. 269-278, 2012.

[2] J. F. Wang, Z. Q. Yan, M. Wang, S. L. Ma, and Y. P. Dai, "Thermodynamic analysis and optimization of an (organic Rankine cycle) ORC using low grade heat source," Energy, vol. 49, no. 1, pp. 356-365, 2013

[3] S. J. Zhang, H. X. Wang, and T. Guo, "Performance comparison and parametric optimization of subcritical Organic Rankine Cycle (ORC) and transcritical power cycle system for low-temperature geothermal power generation," Applied Energy, vol. 88, no. 8, pp. 2740-2754, 2011.

[4] G. Manente, A. Toffolo, A. Lazzaretto, and M. Paci, "An Organic Rankine Cycle off-design model for the search of the optimal control strategy," Energy, vol. 58, no. 1, pp. 97-106, 2013.

[5] A. Algieri and P. Morrone, "Comparative energetic analysis of high-temperature subcritical and transcritical Organic Rankine Cycle (ORC), A biomass application in the Sibari district," Applied Thermal Engineering, vol. 36, pp. 236-244, 2012.

[6] N. J. Zhou, X. Y. Wang, Z. Chen, and Z. Q. Wang, "Experimental study on Organic Rankine Cycle for waste heat recovery from low-temperature flue gas," Energy, vol. 55, no. 15, pp. 216-225, 2013.

[7] L. Pierobon, T. V. Nguyen, U. Larsen, F. Haglind, and B. Elmegaard, "Multi-objective optimization of organic Rankine cycles for waste heat recovery: Application in an offshore platform," Energy, vol. 58, no. 1, pp. 538-549, 2013.

[8] R. S. El-Emam and I. Dincer, "Exergy and exergoeconomic analyses and optimization of geothermal organic Rankine cycle," Applied Thermal Engineering, vol. 59, no. 1-2, pp. 435-444, 2013.

[9] J. F. Wang, Z. Q. Yan, P. Zhao, and Y. P. Dai, "Off-design performance analysis of a solar-powered organic Rankine cycle," Energy Conversion and Management, vol. 80, pp. 150-157, 2014.

[10] M. Marion, I. Voicu, and A. L. Tiffonnet, "Wind effect on the performance of a solar organic Rankine cycle," Renewable Energy, vol. 68, pp. 651-661, 2014.

[11] G. P. Yu, G. Q. Shu, H. Tian, H. Q. Wei, L. Liu, "Simulation and thermodynamic analysis of a bottoming Organic Rankine Cycle (ORC) of diesel engine (DE)," Energy, vol. 51, no. 1, pp. 281-290, 2013.
[12] C. Sprouse III and C. Depcik, "Review of organic Rankine cycles for internal combustion engine exhaust waste heat recovery," Applied Thermal Engineering, vol. 51, pp. 711-722, 2013.

[13] J. Q. Fu, J. P. Liu, C. Q. Ren, L. J. Wang, B. L. Deng, Z. X. Xu, “An open steam power cycle used for IC engine exhaust gas energy recovery," Energy, vol. 44, no. 1, pp. 544-554, 2012.

[14] V. Macián, J. R. Serrano, V. Dolz, J. Sánchez, "Methodology to design a bottoming Rankine cycle, as a waste energy recovering system in vehicles, study in a HDD engine," Applied Energy, vol. 104, pp. 758-771, 2013

[15] B. Peris, J. Navarro-Esbrí, and F. Molés, "Bottoming organic Rankine cycle configurations to increase Internal Combustion Engines power output from cooling water waste heat recovery," Applied Thermal Engineering, vol. 61, no. 2-3, pp. 364-371, 2013.

[16] D. Meinel, C. Wieland, H. Spliethoff, "Effect and comparison of different working fluids on a two-stage organic rankine cycle (ORC) concept," Applied Thermal Engineering, vol. 63, no. 1, pp. 246-253, 2014.

[17] Z. Hajabdollahi, F. Hajabdollahi, M. Tehrani, and H. Hajabdollahi, "Thermo-economic environmental optimization of Organic Rankine Cycle for diesel waste heat recovery," Energy, vol. 63, no. 15, pp. 142-151, 2013.

[18] A. Domingues, H. Santos, and M. Costa, "Analysis of vehicle exhaust waste heat recovery potential using a Rankine cycle," Energy, vol. 49, pp. 71-85, 2013.

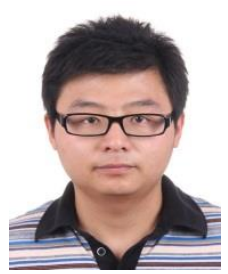

Kai Yang was born in China on February 1, 1987. He got his bachelor's degree from Beijing University of Technology, China in 2005. Now he is a post-graduate student at Beijing University of Technology. His research interests include waste heat recovery and organic Rankine cycle.

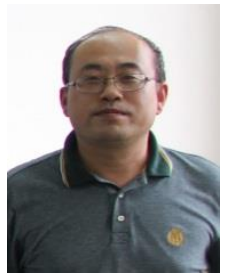

Hongguang Zhang was born in China on February 21,1970 . He got his bachelor's degree, master degree and doctor degree from Beijing Institute of Technology, China, in 1992, 1995, 1998 respectively. From 1998 to 2000, he worked in the Institute of Engineering Thermophysics, Chinese Academy of Sciences as a post doctor. Later he taught at Beijing University of Technology. His research interests include combustion control and energy conservation of internal combustion engine. 